\title{
Deltanet: Network of European Deltas - Sustainable Delta Governance.
}

\author{
Rhoda Ballinger, Cardiff University, UK \\ DeltaNet concerns a European project instigated within the framework of inter-regional cooperation.
}

The goal of the DeltaNet project is to prompt an exchange of know-how and experience between the delta areas throughout Europe. The project has 9 partners: apart from RSD (Belgium and The Netherlands) other partners come from Poland, Germany, the United Kingdom, Portugal, Spain and Romania. It concerns estuarine areas where urbanisation, economic activity (ports) and the natural environment and landscape developments are familiar issues. Eventually the aim is to put such estuarine areas with expressly high and low dynamic functions on the European agenda as specific points for attention.

The European delta areas share many common characteristics, problems and challenges. The delta and estuarine areas are cornerstones of a sustainable area-wide development within a united Europe, where population and the economies are concentrated within such areas; where nature and cultural heritage values have a high priority and where there are important challenges with regard to security (water balance) for future generations. The most important objective for DeltaNet is to set up an educational and policy network for the European delta areas. This network will deal with the various deltas in terms of geography as well as administration. This will guarantee concrete comparative analyses and the extrapolation of applicable insights and results. The various responsibilities in each area of governmental authorities and various institutions present a variety of challenges. DeltaNet will concentrate on the development of the particular mechanisms and processes for promoting a sustainable delta management.

A first step is the exchange of experiences concerning water management (1), ports development (2), environmental issues (3) and the involvement of the various parties concerned (4). From this joint methodologies for integrated management (5) can be determined which, should make it possible for the various different partners to develop specific area-applicable methods for policy and decision making. Finally, recommendations will be put together for various policy levels and for the European Commission. During the entire process, specific attention will be afforded to ensuring the process given as much publicity as possible and as many potential partners and investors will be involved as much as possible.

http://www.delta-net.eu/ 